\title{
ANALISIS UNJUK KERJA RIPv2 DAN EIGRP DALAM DYNAMIC ROUTING PROTOCOL
}

\section{THE PERFORMANCE ANALYSIS OF RIPv2 AND EIGRP ON DYNAMIC ROUTING PROTOCOL}

\author{
Hari Antoni Musril, S.Kom., M.Kom \\ Jurusan Pendidikan Teknik Informatika dan Komputer (PTIK) \\ Institut Agama Islam Negeri (IAIN) Bukittinggi \\ kum_ayik@yahoo.co.id
}

\begin{abstract}
Abstrak
Jaringan komunikasi komputer didukung oleh protokol routing untuk mengirimkan paket data. Ada berbagai jenis protokol routing yang banyak digunakan, diantaranya Routing Information Protocol version 2 (RIPv2) dan Enhanced Interior Gateway Routing Protocol (EIGRP) yang masuk ke dalam dynamic routing protocol. RIPv2 menggunakan protokol distance vector, sedangkan EIGRP dikategorikan pada protokol hybrid. RIPv2 menggunakan request message untuk membangun hubungan dengan router tetangga, sedangkan EIGRP menggunakan hello packet.

Tulisan ini membandingkan kedua protokol tersebut dari aspek daftar tabel routing, informasi mengenai protokol routing, kemampuan menghasilkan tabel topologi, kemampuan mengenali router tetangga (tabel neighbor), melihat konektivitas jaringan, dan memeriksa jalur yang dilewati oleh paket data. Hasilnya adalah EIGRP memiliki konvergensi yang lebih baik dibandingkan RIPv2. RIPv2 melakukan update tabel routing ke seluruh router, sedangkan EIGRP hanya pada router yang terkena dampak langsung dari perubahan topologi jaringan. EIGRP mampu menghasilkan tabel topologi dan tabel neighbor, sedangkan RIPv2 tidak.
\end{abstract}

Kata Kunci : RIPv2, EIGRP, router, routing, protokol

\begin{abstract}
Computer communication network is supported by a routing protocol to transmit data packets. There are different types of routing protocols that are widely used, such as Routing Information Protocol version 2 (RIPv2) and Enhanced Interior Gateway Routing Protocol (EIGRP) that goes into the dynamic routing protocol. RIPv2 using distance vector protocol, whereas EIGRP are categorized in hybrid protocols. RIPv2 use request message to establish relations with the neighboring routers, whereas EIGRP uses hello packet.

This paper analyzes the comparison of both from the aspect of a list of routing table, information about the routing protocol, the ability to generate a topology table, the ability to recognize the neighboring router (neighbor table), see the network connectivity, and check the path of the data packets. The result is EIGRP has better convergence than RIPv2. RIPv2 update its routing table to all routers, while EIGRP only on routers that are directly affected by changes in the network topology. EIGRP is able to produce topology table and neighbor table, but RIPv2 did not.
\end{abstract}

Keywords : RIPv2, EIGRP, router, routing, protocol 


\section{PENDAHULUAN}

Teknologi informasi dan komunikasi (TIK) dapat mempermudah akses terhadap data dan informasi yang sangat dibutuhkan, baik oleh perseorangan maupun lembaga/institusi. TIK salah satunya di dukung oleh adanya teknologi jaringan komputer. Jaringan komputer adalah himpunan "interkoneksi" antara dua komputer autonomous atau lebih yang terhubung dengan media transmisi kabel atau tanpa kabel (wireless) [11]. Dengan adanya teknologi jaringan komputer, maka data dan informasi dapat disampaikan secara cepat, akurat, dan up to date. Bahkan dengan jaringan komputer, perangkat keras seperti printer, scanner, CD/DVD-drive ataupun hardisk serta berbagai program aplikasi dapat juga dibagi (share).

Transmisi data dalam jaringan komputer dapat berlangsung ketika semua syarat yang dibutuhkan untuk terjadinya interkoneksi jaringan komputer telah terpenuhi, baik dari sisi hardware maupun software. Salah satu syarat tersebut adalah setiap device yang ada di jaringan komputer berada dalam network yang sama. Pada jaringan yang besar akan terdapat lebih dari satu network, supaya transmisi data antar network dapat berlangsung dibutuhkan tambahan router. Router adalah piranti elektronik yang fungsinya mem-forward data antara jaringan komputer, dimana software dan hardware diseting untuk melakukan routing dan mem-forward informasi [13].

Router dapat digunakan untuk menghubungkan banyak jaringan kecil ke sebuah jaringan yang lebih besar, yang disebut dengan internetwork, atau untuk membagi sebuah jaringan besar ke dalam beberapa sub network untuk meningkatkan kinerja dan juga mempermudah manajemennya. Router juga digunakan untuk menghubungkan jaringan yang menggunakan media yang berbeda [13]. Router digunakan dalam jaringan berbasis teknologi protokol TCP/IP, untuk melakukan perluasan dari jaringan LAN ke jaringan WAN dan MAN. Contohnya dari jaringan LAN oleh router diperluas menjadi jaringan berbasis internet [5].

Fungsi utama router adalah melewatkan data antar segmen yang memiliki alamat network yang berbeda. Hal ini dapat terjadi karena router memiliki tabel routing yang berisi alamat tujuan [12]. Jadi sebuah router memiliki kemampuan untuk melakukan routing.

Routing adalah proses memilih lintasan yang akan ditempuh oleh sebuah paket pada suatu jaringan komputer untuk mengirim lalu lintas jaringan. Dalam proses routing ini, sebuah jaringan digambarkan sebagai sebuah graf berbobot dimana setiap interkoneksi antar titik dalam jaringan memiliki bobot atau nilai tertentu. Nilai ini dapat berupa bandwith, network delay, hopcount, path cost, load, reliability, dan biaya komunikasi. Setiap router harus mencari rute dengan biaya paling rendah [9].

Terdapat berbagai macam algoritma dalam mengatur proses routing. Aturan tersebut dikenal dengan routing protocol. Pengalamatan jalur/rute paket data yang akan dikirim akan diatur oleh routing protocol ini dengan membentuk tabel routing. Setiap routing protocol memiliki cara dan metode yang berbeda dalam melaksanakan tugasnya. Itulah yang akan menentukan kekuatan dan kelemahan dari masing-masing protokol routing.

RIPv2 dan EIGRP merupakan contoh jenis protokol routing yang dikelompokkan ke dalam dynamic routing protocol. RIP (Routing Information Protocol) versi 2 merupakan salah satu protokol routing distance vector yang menentukan metric berdasarkan pada jumlah lompatan (hop count) untuk pemilihan jalur. Sedangakan EIGRP (Enhanced Interior Gateway Routing Protocol) adalah routing protocol yang menggunakan formula berbasis bandwidth dan delay untuk menghitung metric yang sesuai untuk menentukan rute.

Pada penelitian ini akan merancang sebuah skema topologi jaringan, dimana pada jaringan tersebut digunakan protokol routing RIPv2 dan EIGRP. Kemudian dilakukan serangkaian pengujian untuk melihat perbedaan mendasar antara RIPv2 dan EIGRP. Pengujian tersebut 
difokuskan antara lain pada daftar tabel routing yang dihasilkan, informasi masing-masing protokol routing, hasil tabel topologi, kemampuan mengenali router tetangga (tabel neighbor), kestabilan konektivitas jaringan melalui perintah ping, dan memeriksa jalur yang dilewati oleh sebuah paket data dengan menggunakan perintah tracert. Selanjutnya dilakukan analisa perbandingan RIPv2 dan EIGRP berdasarkan hasil dari beberapa aspek pengujian tersebut. Sehingga akhirnya didapatkanlah kesimpulan yang menunjukkan protokol routing yang lebih unggul.

\section{DASAR TEORI}

\subsection{Dynamic Routing Protocol}

Dynamic routing protocol atau dikenal juga sebagai routing dinamik, merupakan jenis routing dimana router dapat mengenali sendiri jalur/rute terbaik yang akan ditempuh untuk melewatkan paket data dari satu network ke network lainnya. Dynamic routing membuat suatu tabel routing secara dinamik (berubah-ubah secara otomatis) jika topologi jaringan berubah [14].

Dynamic routing protocols secara garis besar diklasifikasikan menjadi EGP dan IGP, yang selanjutnya diklasifikasikan ke dalam distance vector routing dan link state routing. Distance vector routing menggunakan algoritma sederhana untuk menghitung nilai komulatif jarak antar router berdasarkan pada hop count [3]. Dari gambar di bawah ini, RIPv2 dan EIGRP masuk ke dalam klasifikasi distance vector routing.

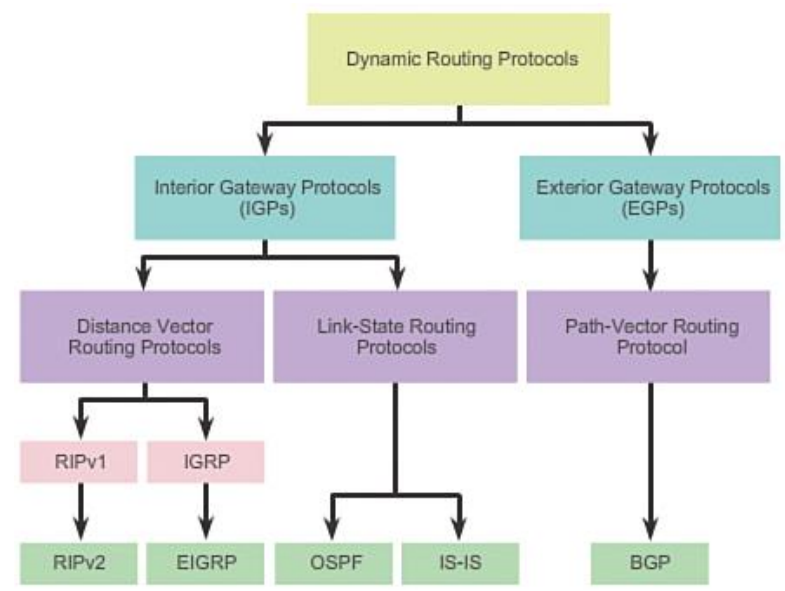

Gambar 1. Klasifikasi Dynamic Routing Protocol [3]

Protokol routing menggunakan istilah yang disebut metric dalam menentukan jalur yang terbaik yang akan dipakai. Metric adalah suatu nilai hasil dari perhitungan algoritma yang dipakai oleh protokol routing yang dapat berupa jarak ke tujuan atau ongkos ke tujuan. Jenis metric yang dipakai bergantung pada jenis prototkol routing yang digunakan, dimana setiap jenis protokol routing menggunakan metric yang berbeda satu dengan lain [14].

\subsection{Routing Information Protocol (RIP)}

Routing Information Protocol (RIP) merupakan protokol distance vector yang menggunakan hitungan lompatan dalam pengukurannya. RIP akan mengirimkan pesan routingupdate pada interval tertentu secara reguler termasuk perubahan-perubahan pada entrinya, sehingga tabel routing-nya akan selalu ter-update. Router RIP akan selalu mempertahankan rute yang terbaik melalui nilai perhitungan terkecil menuju ke tujuannya. Setelah melakukan update pada tabel routing, router tersebut akan segera memulai transmisi updating ke seluruh router jaringan. Update ini sama sekali tidak tergantung dengan update yang secara reguler dilakukan [8]. RIP bekerja 
menggunakan algoritma Bellman-Ford. RIP mengevaluasi jalur terbaik antara host ke tujuan dengan menggunakan metodologi hop count. Hop count dibatasi sampai 15 hop [6].

Sesuai dengan perkembangannya terdapat tiga jenis metode RIP, yaitu RIPv1, RIPv2, dan RIPng. RIP versi 1 (RIPv1) menggunakan classfull routing sehingga tidak bisa mendukung Variable Length Subnet Masks (VLSM). RIPv1 juga tidak mendukung proses autentikasi [6].

Tabel 1. Perbandingan RIPv1 dan RIPv2 [7]

\begin{tabular}{|l|l|}
\hline RIPv1 & RIPv2 \\
\hline Distance Vector & Distance Vector \\
\hline Maximum hop count of 15 & Maximum hop count of 15 \\
\hline Classful & Classless \\
\hline Broadcast based & Uses multicast 224.0.0.9 \\
\hline No support for VLSM & Supports VLSM networks \\
\hline No authentication & Allows for MD5 authentication \\
\hline No support for discontiguous networks & Supports discontiguous networks \\
\hline
\end{tabular}

\section{Mekanisme Kerja RIPv2}

Setelah sebuah topologi jaringan selesai dibangun. RIPv2 akan mem-broadcast sebuah paket berisi request message ke seluruh router tetangga yang ada pada jaringan. Selanjutnya router tetangga yang menerima request message tersebut akan mengirimkan response message yang berisikan tabel routing milik router tetangga. Apabila dari response message tersebut terdapat informasi yang belum dikenali maka router RIPv2 akan memasukkannya ke dalam tabel routing beserta alamat dari router yang mengirimkan respon tersebut. Namun apabila informasi sudah ada sebelumnya dalam tabel routing, maka informasi yang sudah ada itu akan digantikan dengan catatan informasi rute yang baru tersebut memiliki hop count yang lebih rendah.

\subsection{Enhanced Interior Gateway Routing Protocol (EIGRP)}

EIGRP merupakan versi lanjut dari IGRP, yang menawarkan efisiensi operasi yang superior [10]. EIGRP ini adalah protokol routing yang hanya di adopsi oleh router cisco atau sering disebut sebagai Cisco Proprietary distance vector routing protocol.

EIGRP merupakan distance vector protocol yang merawat satu set metric yang kompleks untuk jarak tempuh network-network lain. EIGRP menggabungkan juga konsep link state protocol. Broadcast-broadcast di-update setiap 90 detik ke semua EIGRP router berdekatan. Setiap update hanya memasukkan perubahan network. EIGRP sangat cocok untuk network-network besar [10].

EIGRP juga menggunakan konsep Diffusing Update ALgorithm (DUAL) untuk menghasilkan jalan terbaik mencapai alamat tujuan [4]. DUAL menggunakan dua teknik yang memungkinkan EIGRP untuk melakukan konvergensi dengan cepat. Pertama, setiap router EIGRP menyimpan tabel routing tetangganya. Hal ini memungkinkan router untuk menggunakan rute baru langsung ke tujuan jika rutenya diketahui. Jika tidak ada rute yang diketahui berdasarkan informasi routing sebelumnya dari router tetangga, router EIGRP akan aktif menuju alamat tujuan dan mengirim pesan ke setiap router tetangga untuk mendapatkan rute alternatif menuju tujuan tersebut. Pesan tersebut tetap akan terkirim sampai rute alternatif ditemukan. Router yang tidak terpengaruh oleh perubahan topologi tidak akan memberikan respon terhadap pesan yang dikirimkan [1].

EIGRP akan meng-update tabel routing ketika terjadi perubahan. Informasi perubahan tersebut hanya dikirimkan pada router yang terpengaruh langsung akibat perubahan topologi. Karena itu EIGRP sangat efisien dalam penggunaan bandwith. EIGRP menggunakan tambahan 
bandwith untuk protokol HELLO yang digunakan untuk memonitor status koneksi dengan router tetangga [1].

\section{Mekanisme Kerja EIGRP}

EIGRP melakukan proses routing untuk mencari rute terbaik dengan menghasilkan tiga buah informasi tabel, yaitu tabel neighbor berisikan informasi mengenai semua router yang terhubung ke dirinya atau membentuk hubungan bertetangga (neighbourship), kemudian tabel topologi yang menyimpan semua informasi rute yang dihasilkan dari router tetangga, dan terakhir adalah tabel routing yang memuat informasi mengenai semua router tetangga yang masih terhubung dan rute terbaik untuk mencapai router tersebut. Untuk pertama kalinya ketika topologi jaringan dibangun, EIGRP akan mengenali router tetangga dimana interface yang terhubung langsung ke router tetangga memiliki distance nol dan akan bertambah satu jika telah berpindah ke router tetangga selanjutnya. Semua informasi tersebut disimpan di dalam tabel routing.

Setelah tabel routing terbentuk, langkah selanjutnya adalah EIGRP akan mengirimkan hello packet untuk mengetahui kondisi semua router tetangganya apakah masih hidup atau mati. Pesan hello packet ini dikirim secara simultan, dimana dalam pesan tersebut terdapat hold time yaitu waktu maksimal yang diberikan untuk menunggu balasan pesan dari router tetangga. Apabila router tetangga tidak membalas pesan hello packet tersebut dalam rentang waktu yang telah ditentukan, maka router tetangga tersebut dinyatakan mati. Hal ini menyebabkan EIGRP akan melakukan update terhadap tabel routing-ya. Pada EIGRP update tabel routing dilakukan apabila terjadi perubahan pada network, dimana paket update memuat informasi perubahan jalur/rute yang akan dikirimkan ke router tetangga.

Berikutnya dengan algoritma DUAL (Diffusing Update Algorithm) EIGRP akan menentukan jalur terbaik untuk mencapai tujuan. DUAL melakukan perhitungan untuk menentukan router yang akan ditunjuk menjadi succesor dan menjadi feassible successor. Successor merupakan jalur utama dan jalur yang terdekat serta paling efisien untuk menuju ke sebuah network tujuan. Feasible successor adalah jalur backup atau jalur cadangan yang akan dipakai apabila router successor-nya dalam keadaan down.

\subsection{Perbandingan RIPv2 dan EIGRP}

Berikut ini adalah tabel yang menggambarkan perbandingan secara umum antara RIPv2 dan EIGRP.

Tabel 2. Perbandingan RIPv2 dan EIGRP [2]

\begin{tabular}{|l|l|l|}
\hline \multicolumn{3}{|l|}{ Protocol Comparison } \\
\hline Feature & RIPv2 & EIGRP \\
\hline Type & Distance vector & Hybrid \\
\hline Algorithm & Bellman- ford & DUAL \\
\hline Class full/class less & Class less & Class less \\
\hline Metric & Hop count & Bandwidth/delay \\
\hline Timers update (Hello/Dead) & 30 sec & Triggered (LAN 5/15, WAN 60/180) \\
\hline Administrative distance & 120 & Internal 90, External 170 \\
\hline Authentication & Yes & MD5 Authentication \\
\hline Hop limit & 15 & None \\
\hline Convergence & Slow & Very fast \\
\hline Type of updates & Full table & Only changes \\
\hline Support VLSM & Yes & Yes \\
\hline Network size & Small & Large \\
\hline Split Horizon Sensitive & No & Yes \\
\hline Area Types & - & - \\
\hline
\end{tabular}




\section{HASIL DAN PEMBAHASAN}

\subsection{Topologi Jaringan}

Topologi jaringan untuk penelitian analisis unjuk kerja RIPv2 dan EIGRP ini adalah seperti gambar di bawah.

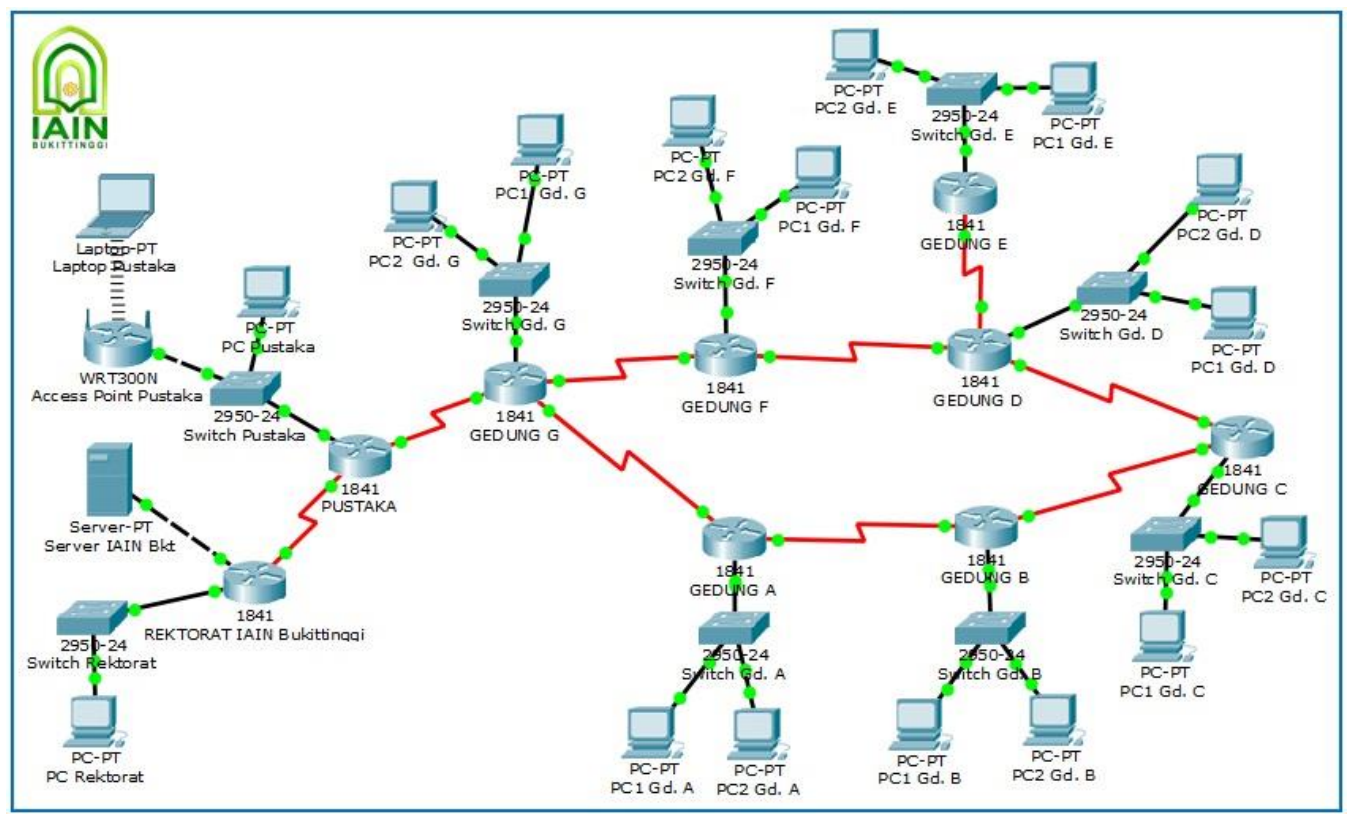

Gambar 2. Topologi Jaringan untuk Penelitian RIPv2 dan EIGRP

\subsection{Konfigurasi Router}

Selanjutnya pengaturan pada jendela IOS Command Line Interface di masing-masing router dengan sintak seperti berikut ini (contoh pada router Rektorat).

Router REKTORAT :

Router(config)\#interface Serial0/0/0

Router(config-if)\#clock rate 72000

Router(config-if)\#ip address 193.173.3.1 255.255.255.0

Router(config-if)\#interface FastEthernet0/0

Router(config-if)\#ip address 118.97.170.1 255.255.255.0

Router(config-if)\#interface FastEthernet0/1

Router(config-if)\#ip address 193.173.2.1 255.255.255.0

Kemudian dilakukan pengaturan routing pada setiap router yang ada. Untuk protokol routing $\mathrm{RIPv} 2$ dituliskan script seperti berikut ini.

\section{REKTORAT :}

Router > enable

Router\#configure terminal

Enter configuration commands, one per line. End with $C N T L / Z$

Router(config)\#hostname Router-Rektorat

Router-Rektorat(config)\#router rip

Router-Rektorat(config-router)\#version 2
Router-Rektorat(config-router)\#network 193.173.2.0

Router-Rektorat(config-router)\#network 118.97.170.0

Router-Rektorat(config-router)\#network 193.173.3.0

Router-Rektorat(config-router)\#no auto-summary

Sedangkan untuk protokol routing EIGRP dituliskan script sebagai berikut ini.

\section{REKTORAT :}

Router > enable

Router\#configure terminal

Enter configuration commands, one per line. End with $C N T L / Z$
Router-Rektorat(config-router)\#network

193.173.2.0

Router-Rektorat(config-router)\#network

118.97.170.0 
Router(config)\#hostname Router-Rektorat Router-Rektorat(config)\#router eigrp 10
Router-Rektorat(config-router)\#network 193.173.3.0

Router-Rektorat(config-router)\#no auto-summary

\subsection{Analisis Perbedaan RIPv2 dan EIGRP}

Pada tahapan analisis ini yang dilihat diantaranya daftar tabel routing yang dihasilkan, informasi protokol routing, tabel topologi, kemampuan mengenali router tetangga (tabel neighbor), melihat konektivitas jaringan, dan memeriksa jalur yang dilewati oleh paket data.

\subsubsection{Tabel Routing}

Untuk memeriksa tabel routing, pada router diketikkan perintah show ip route. Dari hasil yang didaptkan, label huruf "C" mengindikasikan direct connection atau koneksi langsung router tersebut secara fisik dengan suatu network menggunakan interface tertentu. Label " $\mathrm{R}$ " mengindikasikan RIP dan label "D" berarti EIGRP, yang merupakan indirect connection menuju router tersebut. Tanda kurung siku mengindikasikan [administrative distance / metric] untuk rute itu, dimana terdapat perbedaan antar RIPv2 dan EIGRP.

\subsubsection{Informasi Protokol Routing}

Keterangan mengenai protokol RIPv2 pada gedung $\mathrm{G}$ adalah sebagai berikut.

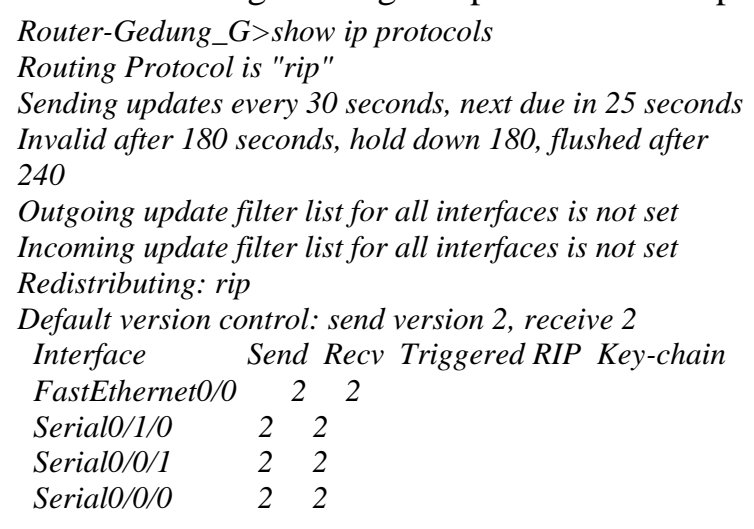

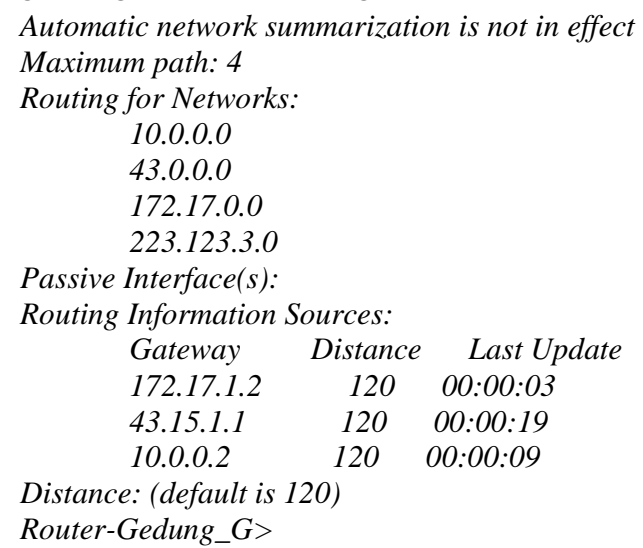

Sedangkan berikut ini adalah keterangan protokol EIGRP pada gedung G.

Router-Gedung_G>show ip protocols

Routing Protocol is "eigrp 10 "

Outgoing update filter list for all interfaces is not set

Incoming update filter list for all interfaces is not set

Default networks flagged in outgoing updates

Default networks accepted from incoming updates

EIGRP metric weight $K 1=1, K 2=0, K 3=1, K 4=0$,

$K 5=0$

EIGRP maximum hopcount 100

EIGRP maximum metric variance 1

Redistributing: eigrp 10

Automatic network summarization is not in effect

Maximum path: 4

\author{
Routing for Networks: \\ 43.0.0.0 \\ 223.123.3.0 \\ 172.17.0.0 \\ 10.0.0.0 \\ Routing Information Sources: \\ Gateway Distance Last Update \\ 172.17.1.2 $90 \quad 5892$ \\ $\begin{array}{lll}10.0 .0 .2 & 90 & 7100\end{array}$ \\ 43.15.1.1 $90 \quad 9467$ \\ Distance: internal 90 external 170 \\ Router-Gedung_G>
}

\subsubsection{Tabel Topologi}

Tabel topologi berisi informasi semua network destination yang di advertise oleh router tetangga (neighbor), dan untuk setiap network destination akan dipilih satu jalur/path terbaik yang kemudian akan disimpan ke dalam tabel routing. Tabel topologi di update setiap kali ada perubahan pada network yang terhubung langsung atau pada interface atau ada pemberitahuan 
perubahan pada suatu jalur dari router tetangga. Untuk melihat tabel topologi pada EIGRP, dituliskan sintak show ip eigrp topology.

\subsubsection{Tabel Neighbor}

Tabel neighbor berisi semua router neighbor. Ketika router menemukan dan menjalin hubungan adjacency (ketetanggaan) dengan neighbor baru, maka router akan menyimpan address router neighbor beserta interface yang dapat menghubungkan dengan neighbor tersebut sebagai satu entri dalam tabel neighbor. RIPv2 tidak memiliki tabel neighbor, sedangkan pada EIGRP terdapat tabel neighbor ini. Sintak untuk melihat tabel neighbor adalah show ip eigrp neighbor.

\subsubsection{Konektivitas Jaringan}

Konektivitas jaringan diuji dengan perintah ping, yang merupakan protokol ICMP (Internet Control Messaging Protocol). Ping (Packet Internet Groper) digunakan untuk memeriksa konektivitas sebuah interface pada suatu jaringan dengan cara mengirimkan paket data ICMP echo request kepada interaface tersebut, lalu menunggu balasan paket data yang disebut ICMP echo response. Untuk menguji konektivitas jaringan ini, dilakukan pengiriman paket ping dari PC1 gedung $\mathrm{G}$ ke $\mathrm{PC} 2$ gedung $\mathrm{C}$.

\subsubsection{Jalur Paket Data}

Perintah tracert digunakan untuk mencari jalur yang akan dilalui oleh paket data, tracert ini menggunakan protokol ICMP. Untuk menguji konektivitas jaringan ini, dilakukan perintah tracert dari PC1 gedung G ke PC2 gedung C.

Hasilnya terdapat perbedaan tracert route pada nomor empat. Pada RIPv2 melewati alamat 212.10.0.1 yang merupakan jaringan yang melewati router pada gedung B. Sedangkan pada EIGRP menempuh alamat 19.21.2.2 yang merupakan jaringan yang melewati router pada gedung D.

\section{KESIMPULAN}

a. Terdapat perbedaan cara update tabel routing, dimana RIPv2 melakukan update ke seluruh router, sedangkan EIGRP hanya melakukan pada router yang terkena dampak dari perubahan yang terjadi pada topologi jaringan.

b. EIGRP dapat menghasilkan tabel topologi dan tabel neighbor, sedangkan RIPv2 tidak didukung dengan kemampuan seperti itu. Hal ini terjadi karena EIGRP menggunakan protokol link-state.

c. EIGRP memiliki konvergensi yang lebih baik dibandingkan RIPv2. Konvergensi merupakan waktu yang dibutuhkan oleh router untuk melalui alternatif jalur/rute agar sampai ke tujuan.

d. Pada tabel routing terdapat perbedaan distance dan metric, RIPv2 memiliki distance sebesar 120, sedangkan EIGRP sebesar 90.

e. Menggunakan perintah ping untuk pengiriman 4 buah paket sebesar 32 bytes dari PC1 gedung $\mathrm{G}$ ke $\mathrm{PC} 2$ gedung $\mathrm{C}$, didapatkan hasilnya adalah RIPv2 memiliki rata-rata approximate round trip time selama $8 \mathrm{~ms}$, sedangkan EIGRP lamanya adalah $7 \mathrm{~ms}$.

f. Tracert route RIPv2 juga berbeda dengan EIGRP pada saat pemilihan jalur dari PC1 gedung G ke PC2 gedung C, dimana RIPv2 melewati router pada gedung B sedangkan EIGRP memilih router gedung D. 


\section{Daftar Pustaka:}

[1] Andal, Vangala R. Mei 2014. Evaluation of EIGRP and OSPF Routing Protocols for Greener Internetworking. (IJETTS) International Journal of Emerging Trends in Technology and Sciences. ISSN : 2348-0246. Volume: 02 Issue: 03. Hal. 181-188. http://www.ijetts.org/admin/issues/IJETTS\%20-\%20020301.pdf. Diakses Tanggal 3 Oktober 2015, Pukul 13.45 WIB.

[2] Archana C. Maret 2015. Analysis of RIPv2, OSPF, EIGRP Configuration on router Using CISCO Packet tracer. (IJESIT) International Journal of Engineering Science and Innovative Technology. ISSN : 2319-5967. Volume: 4 Issue: 2. Hal. 215-222. http://www.ijesit.com/Volume\%204/Issue\%202/IJESIT201502_30.pdf. Diakses Tanggal 3 Oktober 2015, Pukul 16.46 WIB.

[3] Asher, Priya. September 2015. Comprehensive Analysis of Dynamic Routing Protocols in Computer Networks. (IJCSIT) International Journal of Computer Science and Information Technologies. ISSN : 0975-9646. Vol. 6 (5). Hal. 4450-4455. http://www.ijcsit.com/docs/Volume\%206/vol6issue05/ijcsit2015060564.pdf. Diakses Tanggal 1 Oktober 2015, Pukul 10.15 WIB.

[4] Hinds, A., Atojoko A., Zhu, Shao Y. Agustus 2013. Evaluation of OSPF and EIGRP Routing Protocols for IPv6. (IJFCC) International Journal of Future Computer and Communication. ISSN : 2010-3751. Vol. 2 No. 4. Hal. 287-291. http://www.ijfcc.org/papers/169-C005.pdf. Diakses Tanggal 2 Oktober 2015, Pukul 14.23 WIB.

[5] Irwansyah, E., Moniaga, J.V. 2014. Pengantar Teknologi Informasi. Yogyakarta : Deepublish. Hal : 169.

[6] Kaur, A., Singh, P. Juli 2015. Behavior of OSPFV3 and RIPng with Remote Login, HTTP, and E- mail Profiles Using Opnet14.5. (IRJET) International Research Journal of Engineering and Technology. e-ISSN : 2395-0056, p-ISSN : 2395-0072. Volume: 02 Issue: 04. Hal. 908-914. https://www.irjet.net/archives/V2/i4/Irjet-v2i4154.pdf. Diakses Tanggal 2 Oktober 2015, Pukul 09.23 WIB.

[7] Lammle, Todd. 2011. CCNA Cisco Certified Network Associate Study Guide, 7th Edition. Indianapolis : Wiley Publishing Inc. Hal : 400.

[8] Mulyanta, Edi S. 2005. Pengenalan Protokol Jaringan Wireless Komputer. Yogyakarta : Andi Offset. Hal : 123.

[9] Nugroho, Heru. 2015. Matematika Diskrit dan Implementasinya dalam Dunia Teknologi Informasi. Yogyakarta : Deepublish. Hal : 8-9.

[10] Rafiudin, Rahmat. 2003. Mengupas Tuntas Cisco Router. Jakarta : PT. Elex Media Komputindo. Hal : 137, 151.

[11] Syafrizal, Melwin. 2005. Pengantar Jaringan Komputer. Yogyakarta : Andi Offset. Hal : 2.

[12] Wahana Komputer. 2006. SPP Menginstalasi Perangkat Jaringan Komputer. Jakarta : PT. Elex Media Komputindo. Hal : 104-105.

[13] Wahana Komputer. 2010. Cara Mudah Membangun Jaringan Komputer \& Internet. Jakarta : Mediakita. Hal : 16-17.

[14] Wijaya, Hendra. 2006. Belajar Sendiri Cisco ADSL Router, PIX Firewall, dan VPN. Jakarta : PT. Elex Media Komputindo. Hal : 47-48. 